cells made further progress. The report also includes notes on various researches in the field of industrial health, such as environmental factors, the prevalence of byssinosis in the cotton textile industry and sickness absenteeism due to accidents, and on a considerable volume of clinical research under the Clinical Research Advisory Committee.

\section{AUTOMATIC COMPUTING ENGINE OF THE NATIONAL PHYSICAL LABORATORY}

$\mathrm{T}$ $\mathrm{HE}$ pilot model of the automatic computing engine (A.C.E.), recently demonstrated at the National Physical Laboratory, is a general-purpose automatic electronic digital computer employing mercury-tube ultrasonic delay-lines for the storage of numerical data and instruction sequences, and using a modified Hollerith reproducing-punch for the input and output of these data on punched cards. Calculation proceeds in the binary scale.

The delay-line storage units are of two lengths, the shorter containing 32 binary digits, referred to as comprising one 'word', and the longer containing 1,024 digits, that is, 32 words. The digit interval is 1 usec.; the recirculation periods of the long and short delay-lines, namely, 32 and 1,024 usec., are called 'major' and 'minor' cycles, respectively. There are eight long and eight short delay-lines, giving a total capacity of 264 words, equivalent to 264 numbers of nine decimal digits and a sign. Although only a pilot model, the machine is able to deal with many problems of worthwhile complexity in which the numbers of instructions involved and intermediate results to be stored are not too great. For a typical problem of this kind, three or four of the long delaylines are in use for instructions.

The arithmetic units comprise an adder and a multiplier. The adder is connected in the recirculation path of one of the short delay-lines, known as the 'accumulator', so that any number transferred to the input of the adder is added to the number in the line. It is also provided with a second input through which a number may be subtracted from that in the line. Addition and subtraction thus take $32 \mu$ sec., the time occupied by the transfer. The multiplier is connected with three short delay-lines, one to hold the first factor and two connected in series to store the second factor, which is afterwards displaced by the product as multiplication proceeds. The latter two lines are available as an accumulator of two words capacity when not in use for multiplication. Multiplication takes 2 msec., but is automatic as soon as it is started, so that other operations can be carried out during the formation of the product.

In addition to the arithmetical operations, the machine is capable of performing certain logical operations. Two of the short delay-lines are connected with $(a)$ a circuit the output of which is the digit 1 when the digits from the lines are both 1 , but is 0 otherwise ; and $(b)$ a circuit the output of which is 1 when the digits from the lines are either $(1,0)$ or $(0,1)$, but is 0 when they are either $(1,1)$ or $(0,0)$. One of these short lines is also connected with $(c)$ a circuit producing 0 when the line produces 1 and conversely, and $(d)$ a circuit producing the same output as the line but delayed by one digit interval.
The 'logical operations' $(a)$ to (d) are the only manipulative facilities available internally to the machine besides addition, subtraction, multiplication, delaying the output of a long delay-line by one minor cycle, and selection of the last digit of certain of the short lines. The latter is used chiefly for sign-sensing when negative numbers are represented by complements with respect to $2^{32}$.

All computation and manipulation of data are expressed as an equivalent sequence of simple transfers of words, one or more at a time, from one of 32 possible 'sources' to one of 32 'destinations'. Thus, addition of two numbers is achieved by transferring one of them from its current store-position to the accumulator, thereby displacing the previous word in the accumulator, and then transferring the other number to the additive input of the accumulator. Multiplication is initiated by use of a special destination, the factors having first been transferred to the appropriate short lines. Logical operations are performed by first transferring the operands to the associated short lines, and then transferring the result from the output of the appropriate circuit to the destination at which it is required. These circuits operate continually, whether they are in use as sources or not. The transfers are carried out serially, each being specified by an 'instruction' of one word, five of the digits of which determine the source and five the destination. The assimilation of each instruction by the control circuits occupies one minor cycle (32 usec.), so that transfers can take place at the maximum rate of 16,000 per sec.

An instruction may be drawn from any of seven long lines and one short line, as specified by three digits of the instruction previously obeyed, and it in turn will determine where the next instruction is to come from. Each instruction also specifies a waiting period of an integral number of minor cycles before the transfer is to begin, and a transfer period for which it is to take place. These numbers lie in the ranges $0-63$ and $1-64$ respectively, and each is determined by six digits of the instruction word. The instructions are fed continuously to the control circuits from the delay line currently selected; but only the one running in during the last minor cycle of each transfer is accepted and carried out as the next instruction; it will depend upon the wait and transfer numbers of the current instruction. This dependence is modified by the use of a special (and essential) destination called the 'discriminator', when the subsequent course of the computation is to depend upon a result already obtained. When a word composed entirely of zeros is transferred to the discriminator, the next instruction is taken from the normal position in the delay line currently used for instructions; but when a word having some digit 1 is so transferred, the next instruction is taken from the position following the normal one, leading to a different sequence of instructions. All discrimination criteria are capable of expression as the presence or absence of a digit 1 in some word, specially constructed if necessary, so that the above procedure is always adequate.

In addition to the sources and destinations associated with the delay lines and those already mentioned, there are the following: sources of a few useful constant words such as $000 \ldots 0,100 \ldots 0$, 111 ... 1; destinations which initiate a read cycle or a punch cycle in the Hollerith equipment; a source indicating (by emitting the word 111... 1) that the input or output cards are in position for 
reading or punching a row; and a destination providing an external signal to the operator of the machine (a buzzer).

Reading-in and punching of cards are each carried out at the rate of a hundred cards a minute. Each card has 12 rows, and each row can be punched with one word occupying any 32 columns out of an available 80 , as determined by a plugboard. Numbers can be read by the machine from cards punched in standard decimal form, converted to binary form internally by appropriate instruction sequences, and the binary results of calculation reconverted to decimal form and punched, all in the same run.

A number of trial instruction sequences, prepared and used before the multiplier had been installed, included the following :

(1) Determination of the square root of any 31 -digit binary number, to 31 digits. 14 instructions; time 60-90 millisec., depending on the number.

(2) Integration of $1 /\left(1+x^{2}\right)$ from 0 to 1 in 256 equal steps by Simpson's Rule. 57 instructions; time 10 sec., 40 millisec. per step.

(3) Integration of Bessel's equation for $J_{0}(x)$ from 0 to $\frac{1}{4}$ in 4,096 equal steps. 96 instructions; time 52 sec., about 13 millisec. per step.

(4) Determination of the smallest prime factor of any integer less than $4,000,000$. This involves up to 1,000 divisions, each of which occupies 6 millisec. for a dividend of 22 binary digits. 31 instructions ; time less than 7 sec. With 27 further instructions, preliminary decimal-binary and final binary-decimal conversion can be carried out, the whole taking an insignificantly longer time.

(5) Calculation of the position of a set of light rays after passage through any compound lens having prescribed refractive indices and a given number of spherical surfaces. The surfaces were dealt with in separate runs, all rays being computed at each run. 128 instructions; computing time 1 sec. per ray per surface, which is reduced to 0.2 sec. when the automatic multiplier is used.

The work described above has been carried out as part of the research programme of the National Physical Laboratory, and this article is published by permission of the Director of the Laboratory.

M. WOODGER

\section{INDUSTRIAL RELATIONS IN CANADA}

$\mathrm{T}$ HE present state of industrial relations in Canada is described in a recent issue of the journal of the Institute of Personnel Management by Miss E. B. Sharpe, deputy director of the Institute (32, No. 311 ; September-October 1950).

Labour and social legislation are a Provincial and not a Dominion responsibility, although the trend is towards similarity in pattern because big differences in wages and conditions might create unfair competitive conditions between industries located in different Provinces. This trend was stimulated by the emergency powers temporarily vested in the Dominion government during the War, and is encouraged now by annual conferences of representatives from Provincial departments of labour convened to compare the administrative aspects of labour legislation.

The trade union movement is of fairly recent development, and there are still large areas of industry where standards are protected more by legislation on hours, minimum wages, holidays with pay and other working conditions than by collective agreements.

The labour movement of Canada is very closely linked with that of the United States. To-day the movement includes the Trades and Labour Congress of Canada, many of the constituent unions of which are affiliated to the American Federation of Labour; the Canadian Congress of Labour which is similarly linked with the Congress of Industrial Organizations ; the International Kailway Brotherhoods; and the Catholic Syndicates of Quebec, who feel a closer kinship with French and Belgian unions and are often in conflict with the rest.

In 1947 the Dominion Relations Act was passed which regulates relationships in inter-provincial commerce and services. In essentials this follows the pattern of the Provincial Labour Relations Act, so that an outline of the principal provisions of the Act in Ontario can be accepted as accurate in the main for the country as a whole. The Labour Relations Act includes the following principles :

(1) Collective bargaining shall be compulsory.

(2) The right to strike shall be deferred until after conciliation has been fully explored.

(3) Certain practices on the part of both employer and union are declared to be "unfair".

(4) Members of management down to and including supervisory staff shall be excluded from legal recognition as part of the trade union movement.

of current issues in industrial relations, the pensions plan has loomed large since it was ruled a legitimate issue of collective bargaining by the U.S. National Labour Relations Board in the steel dispute about a year ago. Two other issues arouse much feeling in Canadian unions and underline the newness and insecurity which the trade unions still feel. One is the demand for a senjority clause in contracts and the other for a union security clause. The former is sought as a protection against arbitrary lay-off or discharge but can also, if not clearly thought out and worded, hamper efficiency by limiting managements' right to promote and transfer for reasons of ability, skill, health and the like; the latter is often sought as a protection against infiltration by rival unions seeking to get a transfer of certification from the "sitting tenant" to themselves. Union security clauses vary from 'closed shop' (where only union members can be engaged and where workers must remain members to keep their jobs) and 'union shop' (where non-members may be engaged but must become members after a certain period) to a variety of maintenance provisions ; of these, the 'check-off', (the deduction by the company from an employee's pay to cover his union subscriptions), which is irrevocable for the duration of the contract, is at present being frequently demanded.

In general, it is true to say that the trade union. movement in Canada is more accepted and less belligerent than in the United States. The movement is mainly active in collective bargaining and has not interested itself particularly in joint consultation or other forms of participation in management.

An outstanding piece of social legislation is the Workmen's Compensation Act of Ontario, which is followed in pattern, though not quite so liberally in benefits, by the other Provinces. Originating in 1915 , the objects of this legislation are to eliminate litigation with all its attendant uncertainties, delays, expense, and frequent bad psychological effects on the injured workman and to give security of pay- 